\title{
Analysis of Design Parameters of a Novel Modified Reciprocating Mechanism
}

\author{
Emre Arabac1 ${ }^{1 *}$ \\ 0000-0002-6219-7246 \\ ${ }^{1}$ Automotive Technology Department, Vocational School of Technical Sciences, Burdur Mehmet Akif Ersoy University, Burdur, Turkey
}

\begin{abstract}
In this study, displacement, velocity, and acceleration equations were obtained for the mechanism created by modifying the long-stroke reciprocating mechanism. Thus, a novel mechanism has been created. In addition, the effects of the design parameters were examined and the results obtained were compared with the conventional crank-connecting rod mechanism. While the crank radius $(r)$ and connecting rod length $(L)$, which are the main design parameters of the conventional crank-connecting rod mechanism, are fixed, the design parameters of the novel mechanism are changed and the effects of these design parameters on the velocity and acceleration characteristics are examined. For the novel mechanism, the ratio of the inner gear radius to the pinion gear radius $\left(r_{2} / r_{1}=k\right)$ and the ratio of the output gear radius to the pinion gear radius $\left(r_{0} / r_{1}=m\right)$ are determined as the basic design parameters. Accordingly, by decreasing $k$ and increasing $m$, it was seen that the connecting rod angle, mean piston velocity and mean piston acceleration were decreased. The correct choice of $k$ and $m$ shows that the novel mechanism can be made more advantageous compared to the conventional crank-connecting rod mechanism. The results are predicted to be promising for engine designers.
\end{abstract}

Keywords: Crank mechanism, Kinematics, Long-stroke, Reciprocate

\author{
* Corresponding author \\ Emre Arabac1 \\ earabaci@mehmetakif.edu.tr \\ Address: Automotive Technology \\ Department, Vocational School of \\ Technical Sciences, Burdur Mehmet \\ Akif Ersoy University, Burdur, \\ 15100, Turkey
}

Tel: +902482134503

Fax: +902482134598

Research Article

\section{Manuscript}

Received 23.04.2020

Revised $\quad 19.06 .2020$

Accepted 25.06.2020

Doi: 10.30939/ijastech..725750

\section{Introduction}

The first example of the crank-connecting rod mechanism used even in today's modern internal combustion engines is the early crank-connecting rod mechanism of Ismail al-Jazari (also called al-Jazari), one of the important engineers and, inventors of the 11th century $[1,2]$. This simple mechanism, which is frequently used in machine design, converts circular motion to linear (reciprocating) motion and vice versa. In internal combustion engines, the crank-connecting rod mechanism is used to convert the repetitive up-and-down or backand-forth linear motion of the piston into continuous rotary motion in the output shaft. This crank-connecting rod mechanism is called the reciprocating mechanism $[3,4]$.

To create useful work on the output shaft in internal combustion engines, the force that moves the piston down through the gas pressure created by the combustion effect in the cylinder should be transmitted to the connection rod and this force in the connecting rod should be transmitted to the crank. However, many losses occur during this force transmission due to the angular relationships in the crank-connecting rod mechanism. There are many alternative displacement mechanisms developed for internal combustion engines. These mechanisms have been developed to achieve a specified purpose or to improve the existing system. Besides, these mechanisms are modified crank-connecting rods or specially designed mechanisms created by adding various links to the conventional crank-connecting rod mechanism. The compression ratio in the Atkinson cycle is smaller than the expansion ratio. Many mechanisms have been developed to achieve this goal. In 1887, Atkinson added various connections to the crank connecting rod mechanism and created the mechanism in which the compression ratio was smaller than the expansion ratio [5]. A modernized version of Atkinson's design was created by Yamada, and links were created in this mechanism similar to that of Atkinson [6]. Catalano created the CTL engine by making Atkinson more compact. In this design, the elliptical gear mechanism was used instead of the conventional crank connecting rod mechanism [7]. 
Various mechanisms have been developed not only for Atkinson cycle engines but also for conventional engines.

Gültekin and Çinar performed the kinematic and thermodynamic analysis by applying the rhombic drive mechanism to a two-stroke engine and compared the rhombic drive mechanism with the conventional crank-connecting rod mechanism. In this paper, approximately the same performance results were obtained in both mechanisms [8]. Y1lmaz et al. performed a thermodynamic analysis by applying the rhombic drive mechanism to a four-stroke engine. Thanks to the Rhombic drive mechanism, the maximum in-cylinder pressure has been reported to increase by $2 \%$ compared to the conventional crank-connecting rod mechanism [9]. Kopystanski has created a novel crank-connecting rod mechanism for reciprocating engines. In this mechanism, two rack gears are used for piston movement, and this mechanism is claimed to be more efficient compared to the conventional crank-connecting rod mechanism [10]. Many mechanisms have also been created to make a variable stroke in engines [11-14].

One of the interesting mechanisms is the Scotch-yoke mechanism. In this mechanism, the connecting rod, which is connected to the piston, is coupled to a sliding yoke with a slot that engages on a pin on the rotating disc [15]. In the Scotch-yoke mechanism, sinusoidal motion, cosinusoidal velocity, and sinusoidal acceleration occur. Compared to the conventional crank-connecting rod mechanism, it can be used especially in Otto-cycle engines due to the long waiting period that occurs during the change of direction in the Scotch-yoke mechanism. [16, 17]. Various motion characteristics can also be obtained from the slot design changes in the Scotch-yoke mechanism [18, 19].

An alternative to the crank-connecting rod mechanism can be created using various gear mechanisms. Long or shortstroke reciprocating mechanisms are also one of these alternative methods and they consist only of gears. The pinion gear used instead of the crank moves on the inner gears on the connecting rod. There are inner gears and rack-gears on the connecting rod [20]. The pinion gear moves in these gears. Since the pinion gear is axially fixed, the connecting rod follows a special path that moves right-left and back and forth (Figure 1). When the drive mechanism in Figure 1 is used vertically, it is called short-stroke reciprocating mechanism. Although this mechanism is not structurally similar to the Scotch-yoke mechanism, it resembles the scotch-yoke mechanism as a way of working.

Figure 1 shows some of the positions that occur while moving from the bottom dead center (BDC) to the top dead center (TDC) for the long-stroke reciprocating mechanism. In Figure 1(a) the piston is in BDC, in Figure 1(b) the pinion gear is engaged with inner gear, and in Figure 1(c) the pinion gear is engaged with rack-gear. When the piston moves up to $d s$ from BDC to TDC, the drive mechanism moves up to $d e$. When pinion gear moves on rack-gear, de value is maximum. In Figure 1, the follower of the drive mechanism and the teeth of the gears are not intentionally shown.

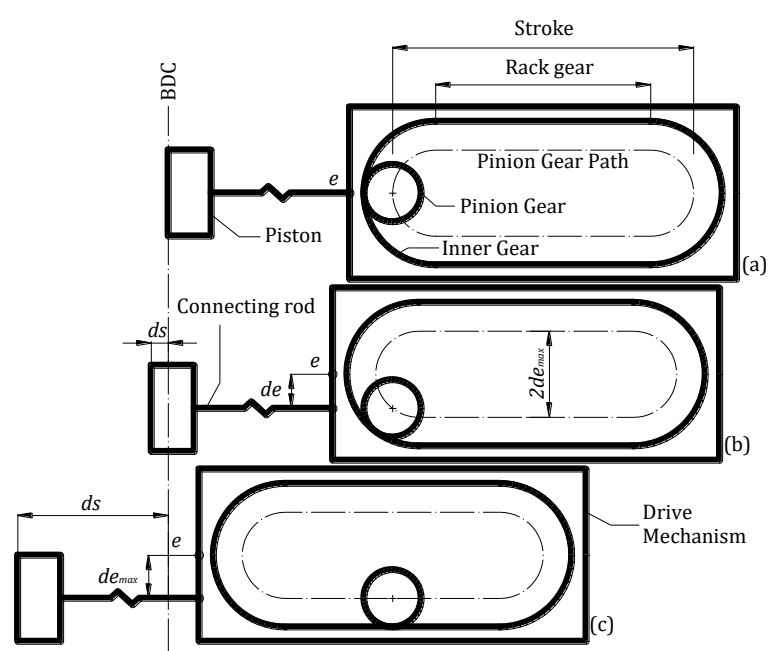

Fig. 1. Long-stroke reciprocating mechanism

In the literature, it is possible to come across various alternative designs for the long-stroke reciprocating mechanism [21-25]. However, Şenberber's design has a different characteristic from other designs [25]. The long-stroke reciprocating mechanism and the crank-connecting rod mechanism are hybridized. In Figure 1, the connecting rod is in motion on the drive mechanism and an eccentricity of up to de occurs between these two elements depending on the pinion gear position. In addition, the connecting rod acts as a pendulum in the conventional crank connecting rod mechanism. In this design of Şenberber, the connecting rod and the drive mechanism are combined into a single structure and turned into a new connecting rod, and therefore this new connecting rod acts like a pendulum just like the conventional crank-connecting rod mechanism (Figure 2).

The drive mechanism on the connecting rod in the novel mechanism acts according to a follower mechanism as in the long stroke reciprocating mechanism. Thanks to this mechanism obtained, mechanical losses caused by angular relationships in the crank-connecting rod mechanism are minimized as much as possible. Thus, it has been claimed that mechanical efficiency of the modified long stroke reciprocating mechanism can be increased compared to the conventional crank-connecting rod mechanism. 


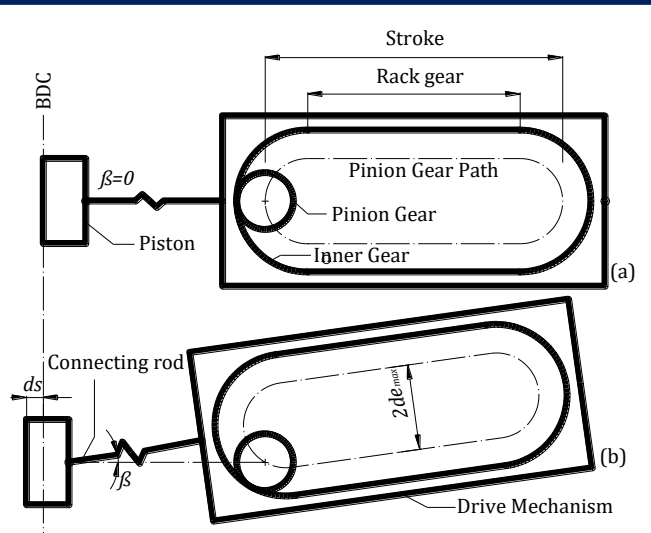

Fig. 2. Novel modified reciprocating mechanism

Alternative designs are also possible for the drive mechanism. A few examples of these designs are presented in Figure 3. Since the kinematic behavior of each design will be different, preference should be made according to the intended use of the mechanism. However, the design scoped in this article is Figure 3(a).
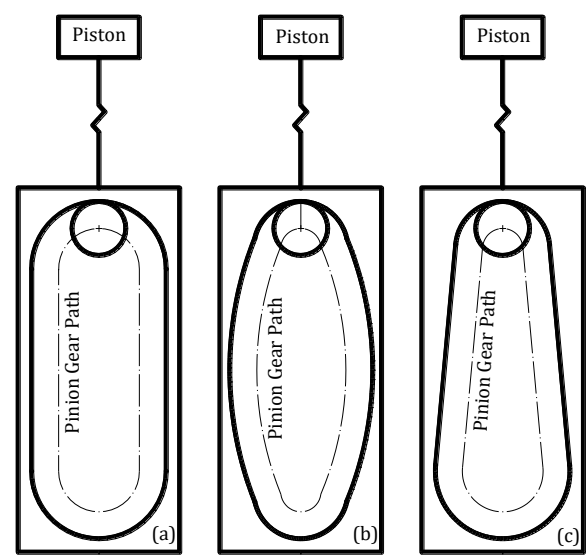

Fig. 3. Alternative designs for the drive mechanism

In this study, a kinematic analysis was performed for a novel modified long stroke reciprocating mechanism, the effects of design parameters were examined and the results were compared with the conventional crank-connecting rod mechanism.

\section{Kinematic Analysis of the Novel Mechanism}

Design parameters and variables and angular relationships are defined for kinematic analysis. Figure 4(a) shows the conventional crankshaft mechanism, and Figure 4(b) shows the nomenclatures used in the calculations for the novel modified long stroke reciprocating mechanism. All created equations are made according to these nomenclatures.

When the conventional crank-connecting rod mechanism in Figure 4(a) is examined, the piston moves $s$ when the output shaft rotates $\theta$ angle. Also, due to the movement of the $B$, $\beta$ angle occurs in the connecting rod. The structure in Figure 4(b) is somewhat more complicated. In Figure 4(a), when the output shaft rotates $\pi$ radians, the piston moves only one stroke.

In Figure 4(b), for the piston to move one stroke, the pinion gear with radius $r_{1}$ must move from $A$ to $D$ by moving on the $A \rightarrow B_{1} \rightarrow C_{1} \rightarrow D$ path. How many turns the pinion gear rotates when reaching from $A$ to $D$ depends on the radius $r_{1}$ and the length of the $A \rightarrow B_{1} \rightarrow C_{1} \rightarrow D$ path. The radius of the $A \rightarrow B_{1}$ and $C_{1} \rightarrow D$ paths is $r_{2}$. For pinion gear to move, $r_{1}$ must be less than $r_{2}$.

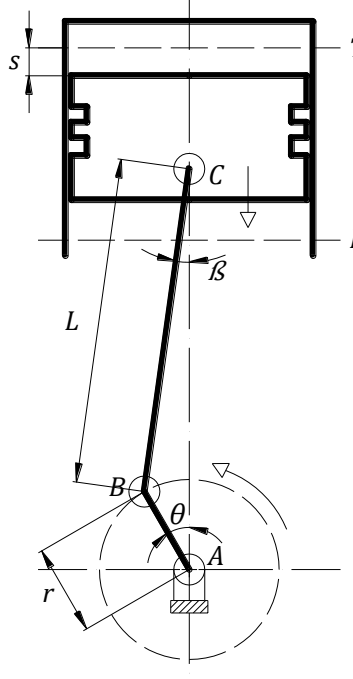

(a)

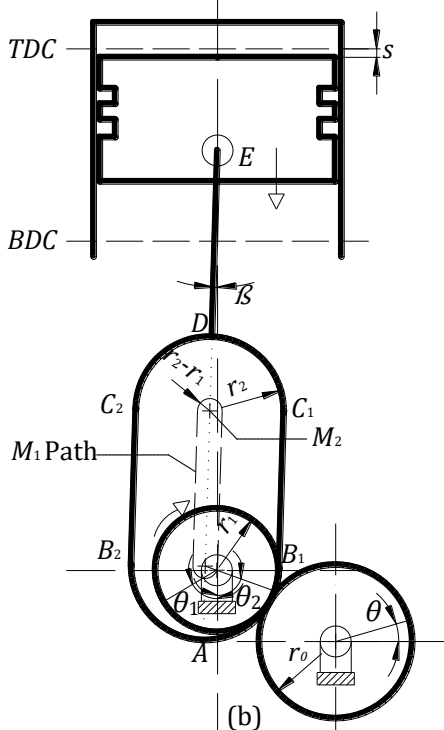

(b)
Fig. 4. Schematic views of mechanisms used for analysis

The relation between $r_{1}$ and $r_{2}$ and the relation between $\theta_{1}$ and $\theta_{2}$ are defined as follows.

$\frac{r_{2}}{r_{1}}=\frac{\theta_{1}}{\theta_{2}}=k$

When the crankshaft gear rotates $\pi$ radians, the pinion gear completes $A \rightarrow B_{1} \rightarrow C_{1} \rightarrow D$ path. Thus, the piston moves up to $h(=2 r)$ and reaches BDC from TDC. Here, $r$ must be $r_{1}$. Therefore, the relation between $r$ and $r_{1}$ and the relation between $\theta$ and $\theta_{1}$ are defined as follows:

$\frac{r_{0}}{r_{1}}=\frac{\theta_{1}}{\theta}=m$

Valid values of $\mathrm{k}$ and $\mathrm{m}$ are expressed as follows: 
$1<k<m$

$1<m=2$

$A \rightarrow B_{1} \rightarrow C_{1} \rightarrow D$ path can be expressed as follows:

$\psi_{A \rightarrow B_{1} \rightarrow C_{1} \rightarrow D}=\pi r=\pi m r_{1}=2 \pi r_{2}+\left|B_{1} C_{1}\right|$

Here, $\left|B_{1} C_{1}\right|$ is expressed as follows:

$\left|B_{1} C_{1}\right|=2\left(r-r_{2}+r_{1}\right)$

Using Eqs. 1-7, $r_{1}$ is defined as follows:

$r_{1}=\frac{2 r}{\pi(m-k)+2(k-1)}$

In order to compare the novel mechanism to the conventional crank connecting rod mechanism, $|A E|$ and $|D E|$ are defined as follows:

$$
\begin{aligned}
& |A E|=L+r+r_{1} \\
& |D E|=L-r-r_{1}
\end{aligned}
$$

In the conventional crank-connecting rod mechanism, the displacement of the piston depending on the crank angle is defined as follows:

$$
s=L+r-\left(L^{2}-r^{2} \sin ^{2} \theta\right)^{1 / 2}-r \cos \theta
$$

The piston displacement for the novel mechanism is quite complex to express with a single equation. For this reason, piston displacement equations are obtained step by step for the novel mechanism. Table 1 presents which piston displacement equation will be used in which $\theta$ angle range.

Table 1. $\theta$ angle ranges for piston displacement equations

\begin{tabular}{|c|c|}
\hline Path & $\theta_{\min } \rightarrow \theta_{\max }$ \\
\hline$A \rightarrow B_{1}$ & $0 \rightarrow \frac{\pi k}{2 m}$ \\
\hline$B_{1} \rightarrow C_{1}$ & $\frac{\pi k}{2 m} \rightarrow \pi\left(1-\frac{k}{2 m}\right)$ \\
\hline$C_{1} \rightarrow D$ & $\pi\left(1-\frac{k}{2 m}\right) \rightarrow \pi$ \\
\hline$D \rightarrow C_{2}$ & $\pi \rightarrow \pi\left(1+\frac{k}{2 m}\right)$ \\
\hline$C_{2} \rightarrow B_{2}$ & $\pi\left(1+\frac{k}{2 m}\right) \rightarrow \pi\left(2-\frac{k}{2 m}\right)$ \\
\hline$B_{2} \rightarrow A$ & $\pi\left(2-\frac{k}{2 m}\right) \rightarrow 2 \pi$ \\
\hline
\end{tabular}

To calculate the piston displacement in the $A \rightarrow B_{1}$, $B_{1} \rightarrow C_{1}$, and $C_{1} \rightarrow D$ paths, the following equations are obtained:

$$
\begin{array}{rl}
s_{A \rightarrow B_{1}}= & L+r \\
& -\left[r_{1}^{2}(k-1)^{2}+\left(L+r-r_{1}(k-1)\right)^{2}\right. \\
& +2 r_{1}(k-1)(L+r \\
& \left.\left.-r_{1}(k-1)\right) \cos \left(\frac{m \theta}{k}\right)\right]^{1 / 2} \\
s_{B_{1} \rightarrow C_{1}}= & L+r \\
& -\left[r_{1}^{2}(k-1)^{2}\right. \\
& +\left(L+r-r_{1}(k-1)\right. \\
& \left.\left.-r_{1}\left(m \theta-\frac{\pi k}{2}\right)\right)^{2}\right]^{1 / 2} \\
s_{C_{1} \rightarrow D} & L+r \\
& -\left[r_{1}^{2}(k-1)^{2}+\left(L-r-r_{1}(k-1)\right)^{2}\right. \\
& -2 r_{1}(k-1)(L-r \\
& \left.\left.-r_{1}(k-1)\right) \cos \left(\frac{m(\pi-\theta)}{k}\right)\right]^{1 / 2} \\
& +r
\end{array}
$$

The $D \rightarrow C_{2} \rightarrow B_{2} \rightarrow A$ path is the symmetry of the $A \rightarrow$ $B_{1} \rightarrow C_{1} \rightarrow D$ path. Accordingly, the following equations can be used in the calculation of piston displacement for $D \rightarrow C_{2}, C_{2} \rightarrow B_{2}$, and $B_{2} \rightarrow A$ paths.

$$
\begin{aligned}
s_{D \rightarrow C_{2}}= & L+r \\
& -\left[r_{1}^{2}(k-1)^{2}+\left(L-r-r_{1}(k-1)\right)^{2}\right. \\
& -2 r_{1}(k-1)(L-r \\
& \left.\left.-r_{1}(k-1)\right) \cos \left(\frac{m(\theta-\pi)}{k}\right)\right]^{1 / 2} \\
s_{C_{2} \rightarrow B_{2}}= & L+r \\
& -\left[r_{1}^{2}(k-1)^{2}\right. \\
& +\left(L+r-r_{1}(k-1)\right. \\
& \left.\left.-r_{1}\left(m(2 \pi-\theta)-\frac{\pi k}{2}\right)\right)^{2}\right]^{1 / 2}
\end{aligned}
$$




$$
\begin{aligned}
S_{B_{2} \rightarrow A}= & +r \\
& -\left[r_{1}^{2}(k-1)^{2}+\left(L+r-r_{1}(k-1)\right)^{2}\right. \\
& +2 r_{1}(k-1)(L+r \\
& \left.\left.-r_{1}(k-1)\right) \cos \left(\frac{m(2 \pi-\theta)}{k}\right)\right]^{1 / 2}
\end{aligned}
$$

The general expression for velocity and acceleration depending on the $\theta$ angle and angular velocity $(\omega)$ is as follows.

$$
\begin{aligned}
& v_{(\theta, \omega)}=\omega \frac{d s}{d \theta} \\
& a_{(\theta, \omega)}=\omega^{2} \frac{d^{2} s}{d \theta^{2}}
\end{aligned}
$$

$\beta$ angle occurs in the connecting rod in both mechanisms. In the conventional crank-connecting rod mechanism, the $\beta$ angle is expressed as follows:

$$
\beta_{A \rightarrow B_{1}}=\sin ^{-1}\left(\frac{r}{L} \sin (\theta)\right)
$$

In the novel mechanism, the $\beta$ angle is expressed as follows.

$$
\begin{aligned}
& \beta_{A \rightarrow B_{1}}=\sin ^{-1}\left(\frac{r_{1}(k-1) \sin \left(\frac{m \theta}{k}\right)}{L+r-s_{A \rightarrow B_{1}}}\right) \\
& \beta_{B_{1} \rightarrow C_{1}}=\sin ^{-1}\left(\frac{r_{1}(k-1)}{L+r-s_{B_{1} \rightarrow C_{1}}}\right) \\
& \beta_{C_{1} \rightarrow D}=\sin ^{-1}\left(\frac{r_{1}(k-1) \sin \left(\frac{m(\pi-\theta)}{k}\right)}{L+r-s_{C_{1} \rightarrow D}}\right) \\
& \beta_{D \rightarrow C_{2}}=\sin ^{-1}\left(\frac{r_{1}(k-1) \sin \left(\frac{m(\theta-\pi)}{k}\right)}{L+r-s_{D \rightarrow C_{2}}}\right) \\
& \beta_{C_{2} \rightarrow B_{2}}=-\sin ^{-1}\left(\frac{r_{1}(k-1)}{\left.L+r-s_{C_{2} \rightarrow B_{2}}\right)}\right) \\
& \beta_{B_{2} \rightarrow A}=-\sin ^{-1}\left(\frac{r_{1}(k-1) \sin \left(\frac{m(2 \pi-\theta)}{k}\right)}{L+r-s_{B_{2} \rightarrow A}}\right)
\end{aligned}
$$

\section{Numerical Study and Results}

In this study, the specifications of a conventional, single cylinder, gasoline engine (Honda GX-270) were taken as reference in order to compare the two mechanisms (Table 2). The dimensions of this engine have been used for both mechanisims, and the design parameters in the novel mechanism have been examined.
Table 2. Specifications of the engine used in calculations

\begin{tabular}{|l|l|}
\hline Stroke volume & $270 \mathrm{~cm}^{3}$ \\
\hline Bore $(D)$ & $77 \mathrm{~mm}$ \\
\hline Stroke $(2 r)$ & $58 \mathrm{~mm}$ \\
\hline Connecting rod $(L)$ & $105 \mathrm{~mm}$ \\
\hline Compression ratio $(\varepsilon)$ & $8.2: 1$ \\
\hline Maximum Power & $6.7 \mathrm{~kW} @ 3600 \mathrm{rpm}$ \\
\hline Maximum Torque & $19.5 \mathrm{Nm} @ 2500 \mathrm{rpm}$ \\
\hline Idling speed & $1400 \mathrm{rpm}$ \\
\hline
\end{tabular}

The design parameters for the new mechanism are the $k$ and $m$ coefficients. These coefficients are defined by Eqs. 1 and 2 and their valid values are determined by Eqs. 3 and 4.

Table 2. $k$ and $m$ coefficient values used for the numerical study

\begin{tabular}{|c|c|c|c|c|c|}
\hline \multirow{2}{*}{$\mathrm{m}$} & \multicolumn{5}{|c|}{$\mathrm{k}$} \\
\hline & 1.1 & 1.3 & 1.5 & 1.7 & 1.9 \\
\hline 1.2 & $\checkmark$ & & & & \\
\hline 1.4 & $\checkmark$ & $\checkmark$ & & & \\
\hline 1.6 & $\checkmark$ & $\checkmark$ & $\checkmark$ & & \\
\hline 1.8 & $\checkmark$ & $\checkmark$ & $\checkmark$ & $\checkmark$ & \\
\hline 2.0 & $\checkmark$ & $\checkmark$ & $\checkmark$ & $\checkmark$ & $\checkmark$ \\
\hline
\end{tabular}

Figure 5 and Figure 6 show the variation of piston displacement due to $\theta$.

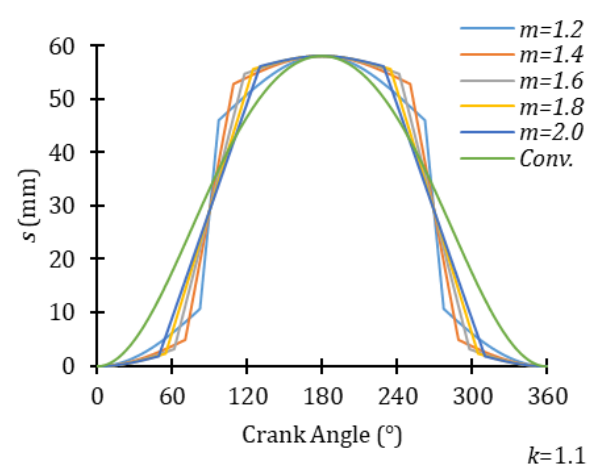

Fig. 5. $s-\theta$ diagram $(k=1.1$ and $m=$ variable $)$

When $k$ is 1.1 , its effect on $s$ in variability of $m$ is shown in Figure 5. As $m$ increases, the displacement of the piston at the dead centers is less. Thus, the quasi-constant volume is created in dead centers. This is particularly advantageous for spark ignition engines. 


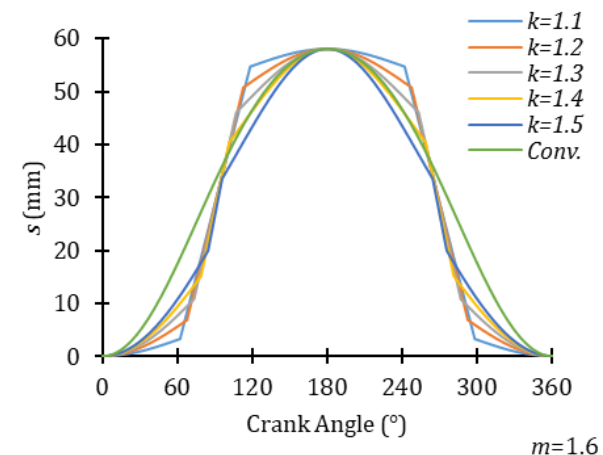

Fig. 6. $s-\theta$ diagram $(m=1.6$ and $k=$ variable $)$

In Figure 6, when the $m$ is 1.6 , the effect of the variability of $k$ on $s$ is shown. As the $k$ increases, the characteristic of the piston displacement curve is similar to the conventional crank-connecting rod mechanism. In order for the quasi-constant volume to occur in dead centers, $k$ should be as low as possible and $m$ should be as high as possible.

Figure 7 and Figure 8 show the variation of $\beta$ due to $\theta$.

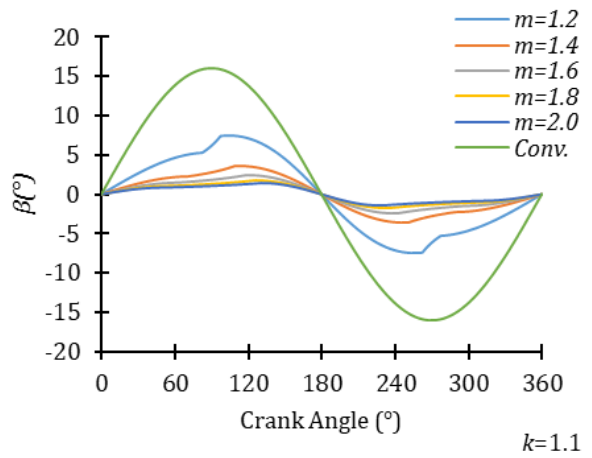

Fig. 7. $\beta-\theta$ diagram $(k=1.1$ and $m=$ variable $)$

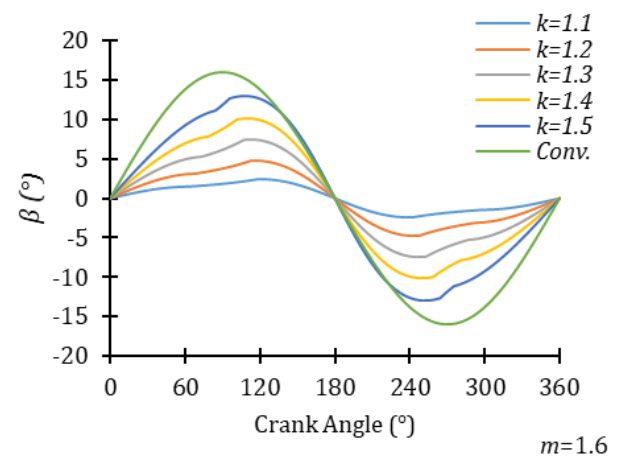

Fig. 8. $\beta-\theta$ diagram $(m=1.6$ and $k=$ variable $)$

In the novel mechanism, $\beta$ is lower than that of the conventional mechanism. The low $\beta$ creates an advantage for force transmission. In Figure 5, $\beta$ decreases as $m$ increases.
In Figure $6, \beta$ increases as $k$ increases. In order for $\beta$ to be low, $m$ should be as high as possible and $k$ should be as low as possible. $\beta$ directly affects the minor and major thrust side forces occurring between the piston-cylinder and is therefore desired to be as small as possible. Because minor and major thrust side forces are a parameter directly affecting mechanical efficiency.

Figure 9 and Figure 10 show the variation of piston velocity due to $\theta$.

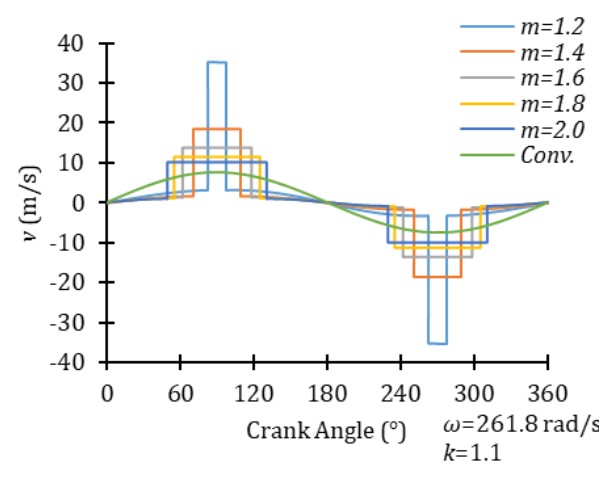

Fig. 9. $v-\theta$ diagram $(k=1.1$ and $m=$ variable $)$

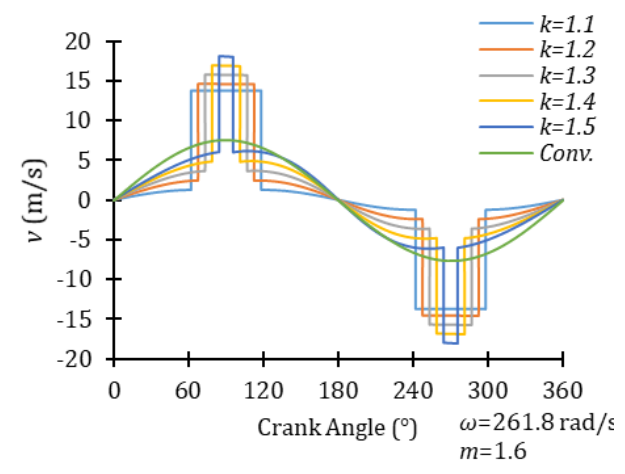

Fig. 10. $v$ - $\theta$ diagram ( $m=1.6$ and $k=$ variable $)$

The change of piston velocity due to $\theta$ in the conventional crank-connecting rod mechanism is sinusoidal. Pick regions formed in the piston velocity diagram of the novel mechanism take place in $B_{1} \rightarrow C_{1}$ and $C_{2} \rightarrow B_{2}$ paths. The angular width of this region indicates how long these paths are. However, since the piston displacement is less in $B_{2} \rightarrow B_{1}$ and $C_{1} \rightarrow C_{2}$ paths in the new mechanism, the piston velocity is also low. Piston velocity suddenly increases, as most of the piston displacement occurs in the $B_{1} \rightarrow C_{1}$ and $C_{2} \rightarrow$ $B_{2}$ paths. In Figure 9 and Figure 10 the output shaft speed was obtained for $2500 \mathrm{rpm}(\omega=261.8 \mathrm{rad} / \mathrm{s})$.

When Figure 9 and Figure 10 are examined, the maximum piston velocity increases as $m$ increases and $k$ increases. However, as $m$ decreases and $k$ decreases, the region where the piston velocity is high (shown angular) is expanding, alt- 
hough the maximum piston velocity decreases. For this, Figure 12 shows the absolute mean velocity of the piston depending on $k$ and $m$. Here, the region called "impossible design region" indicates that the combination of $k$ and $m$ does not comply with the rule in Eq. 3 .

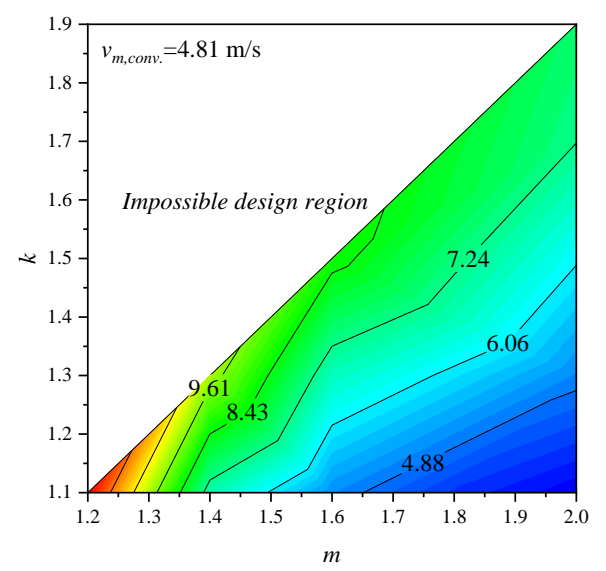

Fig. 11. Mean piston velocity change depending on $k$ and $m$

In Figure 11, the mean velocity decreases with the increase of $m$ or the decrease of $k$. The mean piston velocity of the conventional crank-connecting rod mechanism was calculated as $4.81 \mathrm{~m} / \mathrm{s}$. In the novel mechanism, this value is occured in the region where $m$ is high and $k$ is low.

Figure 12 and Figure 13 show the variation of piston acceleration due to $\theta$ for $2500 \mathrm{rpm}(261.8 \mathrm{rad} / \mathrm{s})$ output shaft speed.

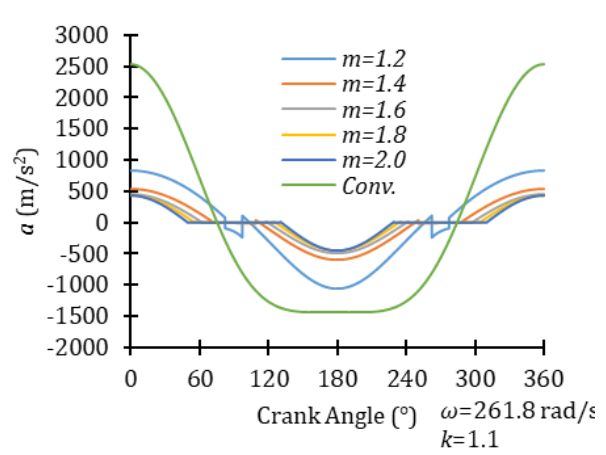

Fig. 12. $v-\theta$ diagram $(k=1.1$ and $m=$ variable $)$

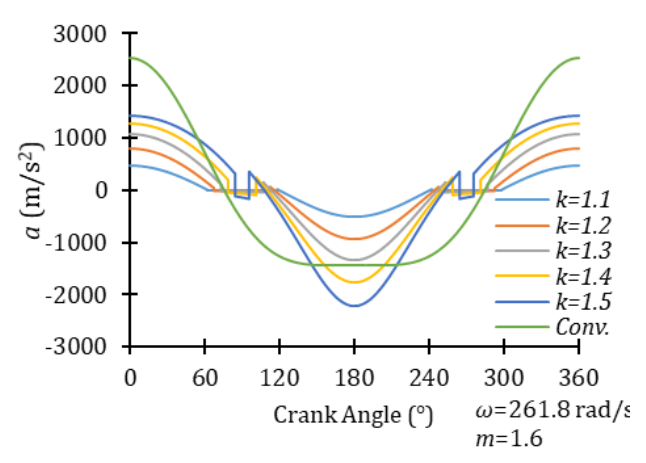

Fig. 13. $a-\theta$ diagram $(m=1.6$ and $k=$ variable $)$

There is a regular acceleration change in the conventional crank connecting rod mechanism. In the novel mechanism, a rapid acceleration change occurs during the transition of the pinion gear from inner gear to rack gear. However, this rapid acceleration change occurs at a limited crank angle. It is seen in Figure 12 that this rapid change in acceleration decreases as $m$ increases. However, as $m$ increases, maximum acceleration decreases. In Figure 13, it is seen that the increase of $k$ increases the piston acceleration.

Figure 14 shows the variation of the absolute mean acceleration of the piston due to $k$ and $m$. It is seen that the mean acceleration did not change much due to the $m$ change, but it was very much affected by the change of $k$. The mean acceleration of the piston also increases with the increase of $k$.

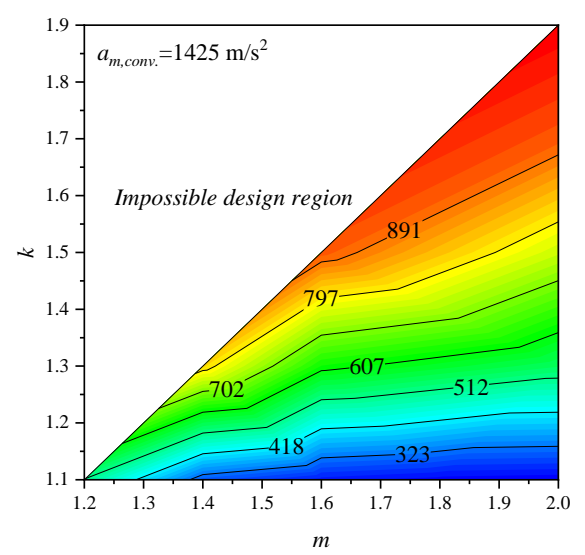

Fig. 14. Mean piston acceleration change depending on $k$ and $m$

$k$ and $m$ coefficients do not only affect piston movement characteristics. These coefficients also directly affect the dimensions of the drive mechanism in the connecting rod. The critical dimension to be examined here is $r_{1}$. The change of $r_{1}$ depending on $k$ and $m$ is presented in Figure 15. 


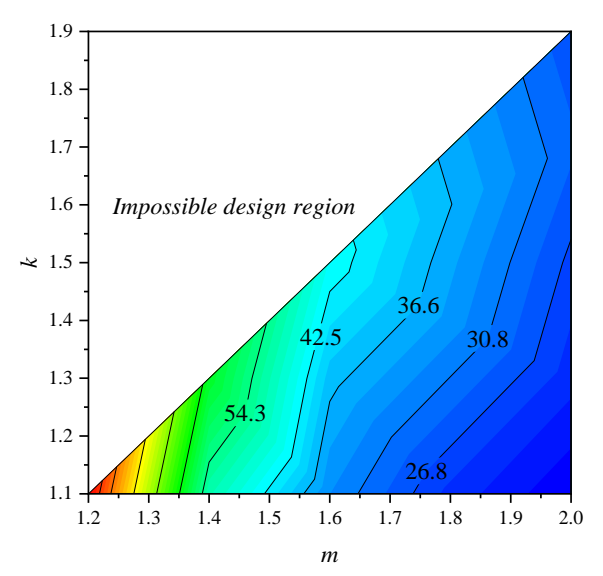

Fig. 15. $r_{1}$ change depending on $k$ and $m$

The small $r_{1}$ reduces the connecting rod working area and weight. For this reason, $r_{1}$ is desired to be small. The main parameter affecting $r_{1}$ is the $m$ coefficient. The coefficient $k$ has no major influence on $r_{1} . r_{1}$ decreases with increasing $m$.

\section{Conclusions}

In this study, displacement, velocity and acceleration equations were obtained for the mechanism created by modifying the long stroke reciprocating mechanism. In addition, the effects of the design parameters were examined and the results obtained were compared with the conventional crankconnecting rod mechanism. This study was intentionally only kinematic analysis. While the crank radius $(r)$ and connecting rod length $(L)$, which are the main design parameters of the conventional crank-connecting rod mechanism, are fixed, the design parameters of the novel mechanism are changed and the effects of these design parameters on the velocity and acceleration characteristics are examined. For the novel mechanism, the ratio of the inner gear radius to the pinion gear radius $\left(r_{2} / r_{I}=k\right)$ and the ratio of the output gear radius to the pinion gear radius $\left(r_{0} / r_{l}=m\right)$ are determined as the basic design parameters. According to this:

- As $k$ increases and $m$ decreases, the displacement characteristic of the piston is similar to the conventional crankconnecting rod mechanism. However, the decrease of $k$ and the increase of $m$ result in quasi-constant volume in dead centers. This can be an advantage especially for spark ignition engines.

- As $k$ decreases and $m$ increases, the connecting rod angle decreases.

- As $k$ decreases and $m$ increases, mean piston velocity and mean piston acceleration decrease.

- Small pinion gear radius ensures that the drive mechanism in the connecting rod is also small. This depends on the low $m$.

As a general assessment, the correct selection of $m$ and $k$ shows that the novel mechanism can be made more advantageous compared to the conventional crank-connecting rod mechanism. The results are predicted to be promising for engine designers.

\section{Nomenclature}

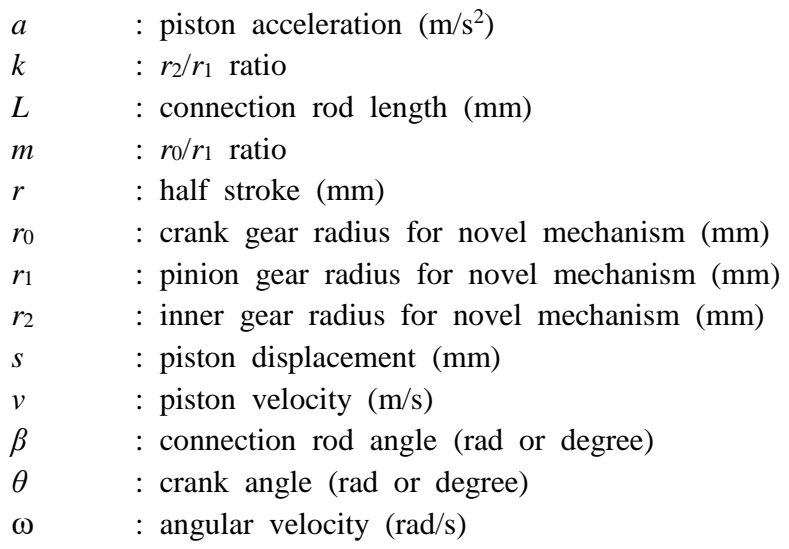

\section{References}

[1] Ceccarelli, M. (Ed.). (2007). Distinguished figures in mechanism and machine science: Their contributions and legacies. Springer Science \& Business Media.

[2] Zhang, C., \& Yang, J. (2020). Ancient Machines. In A History of Mechanical Engineering. Springer, Singapore.

[3] Van Basshuysen, R., \& Schäfer, F. (2004). Internal combustion engine handbook-basics, components, systems and perspectives (Vol. 345).

[4] Rangwala, A. S., Amromin, E. L., \& Kovinskaya, S. (2001). Reciprocating machinery dynamics: design and analysis. Appl. Mech. Rev., 54(5), B80-B81.

[5] Atkinson, J. (1887). U.S. Patent No. 367,496. England: U.S. Patent and Trademark Office.

[6] Yamada, Y. (2003). U.S. Patent No. 6,820,577. Tokyo: U.S. Patent and Trademark Office.

[7] Catalano, G. (2017). WPO Patent No WO 2017/001986 Al. Lugano, China: World Intellectual Property Organization.

[8] Gultekin, E., \& Cinar, C. (2019). A thermodynamic comparison of rhombic-drive and slider-crank mechanisms for a twostroke SI engine. Energy Sources, Part A: Recovery, Utilization, and Environmental Effects, 1-18.

[9] Yılmaz, E., Polat, S., Solmaz, H., Aksoy, F., \& Çınar, C. Buji ile ateşlemeli tek silindirli bir motorda krank-biyel ve rhombic hareket mekanizmalarının termodinamik olarak karşılaştırılması. Gazi Üniversitesi Mühendislik Mimarlık Fakültesi Dergisi, 35(2), 595-606.

[10]Kopystanski, G. (1999). U.S. Patent No. 5,934,243. Washington, DC: U.S. Patent and Trademark Office. 
[11]Nelson, C. D. (1985). U.S. Patent No. 4,517,931. Washington, DC: U.S. Patent and Trademark Office.

[12]Hiyoshi, R., Nakamura, K., \& Sugita, T. (2018). U.S. Patent No. 10,001,056. Washington, DC: U.S. Patent and Trademark Office.

[13]Yang, S., \& Lin, J. (2018). A theoretical study of the mechanism with variable compression ratio and expansion ratio. Mechanics Based Design of Structures and Machines, 46(3), 267284.

[14]Hiyoshi, R., Ushijima, K., Yasuda, Y., \& Moteki, K. (2005). U.S. Patent No. 6,920,847. Washington, DC: U.S. Patent and Trademark Office.

[15]De Witt, C. (1945). U.S. Patent No. 2,366,237. Washington, DC: U.S. Patent and Trademark Office.

[16]B2 Raffaele, P. R., \& Raffaele, M. J. (2007). U.S. Patent No. 7,210,397. Washington, DC: U.S. Patent and Trademark Office.

[17]Close, W. H., Szydlowski, W., \& Downton, C. (1994). Perfect engine balance via collins Scotch Yoke technology (No. 941039). SAE Technical Paper.

[18]Vaux, M. A., \& Denner, T. R. (1994). U.S. Patent No. $5,331,926$. Washington, DC: U.S. Patent and Trademark Office.

[19]Heniges, W. B. (1984). U.S. Patent No. 4,485,768. Washington, DC: U.S. Patent and Trademark Office.

[20]Rane, M. V., \& Uphade, D. B. (2017, August). Novel Long Stroke Reciprocating Compressor for Energy Efficient Jaggery Making. In IOP Conference Series: Materials Science and Engineering (Vol. 232, No. 1, p. 012004). IOP Publishing.

[21]Yadegar, I. (1996). U.S. Patent No. 5,528,946. Washington, DC: U.S. Patent and Trademark Office.

[22]Dunn, J. C. (1958). U.S. Patent No. 2,821,861. Washington, DC: U.S. Patent and Trademark Office.

[23]McClure, K. S. (1984). U.S. Patent No. 4,430,902. Washington, DC: U.S. Patent and Trademark Office.

[24]Senberber, G. (2013). Turkish Patent No. 2013/12131. Ankara, Turkey, DC: Turkish Patent and Trademark Office.

[25]Senberber, G. (2014). Turkish Patent No. 2014/00721. Ankara, Turkey, DC: Turkish Patent and Trademark Office. 